\title{
Medievalista
}

Online

$30 \mid 2021$

Número 30

un nouveau document pour un vieux débat

\section{Le Temple, le Portugal et l'Orient latin}

un nouveau document pour un vieux débat

The Templar Order, Portugal, and the Latin East: A New Document for an Old

Debate

Philippe Josserand

\section{OpenEdition}

Journals

Édition électronique

URL : https://journals.openedition.org/medievalista/4509

DOI : 10.4000/medievalista.4509

ISSN : 1646-740X

Éditeur

Instituto de Estudos Medievais - FCSH-UNL

Référence électronique

Philippe Josserand, « Le Temple, le Portugal et l'Orient latin », Medievalista [En ligne], 30 | 2021, mis en ligne le 01 juillet 2021, consulté le 24 juillet 2021. URL : http://journals.openedition.org/medievalista/ 4509 ; DOI : https://doi.org/10.4000/medievalista.4509

Ce document a été généré automatiquement le 24 juillet 2021.

\section{(c) (†) \&}

Mediavalista está licenciado com uma Licença Creative Commons - Atribuição-NãoComercial 4.0 Internacional. 
un nouveau document pour un vieux débat

\title{
Le Temple, le Portugal et l'Orient
}

\section{latin}

\author{
un nouveau document pour un vieux débat \\ The Templar Order, Portugal, and the Latin East: A New Document for an Old \\ Debate
}

Philippe Josserand

\section{NOTE DE L'ÉDITEUR}

Data recepção do artigo / Received for publication: 29 de Setembro de 2020

Data aceitação do artigo / Accepted in revised form: 18 de Março de 2021

1 Par jeu tout à la fois et par admiration pour un écrivain majeur, singulier et lui-même excessivement joueur, j'ai commencé en 2019 mon étude sur Jacques de Molay par les mots de Fernando Pessoa: "Ne jamais oublier le martyr Jacques de Molay, grand-maître des Templiers, et combattre, toujours et partout, ses trois assassins: l'Ignorance, le Fanatisme et la Tyrannie"1. Quatre ans plus tôt, j'avais déjà recouru à cette phrase où le poète, le 30 mars 1935, dans l'un de ses derniers textes, résumait la notice biographique

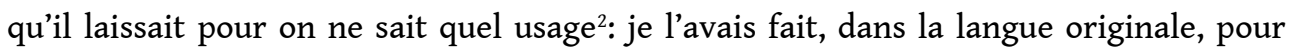
introduire ma communication du VII Encontro sobre ordens militares qui ouvrait la section intitulée "Em Portugal como lá fora: a Ordem do Templo em tempos de mudança (1274-1314)"3. Le tour des images lusitaniennes viendrait, écrivis-je ${ }^{4}$; il attendra encore, mais, touché de l'invitation de Medievalista, j'ai grande joie à me transporter mentalement sur les bords du Tage et à présenter ici, fût-ce de manière brève, le Temple et le Portugal dans leurs liens avec l'Orient latin à la faveur d'un document récemment mis au jour à l'Archivo de la Corona de Aragón, à Barcelone, qui en souligne et - plus rare encore - en illustre, pour partie au moins, le caractère vital et concret. Invoquer de telles relations à l'échelle de la Méditerranée étonnera sans doute plus 
d'un lecteur. Au Portugal, en effet, l'histoire de l'ordre du Temple est encore souvent perçue selon un prisme national. Nombre d'écrits templaristes, débiteurs de Pessoa, mais dépourvus de son génie, en sont même arrivés à identifier le pays et l'institution. En 1977, le philosophe spiritualiste António Telmo soutenait ainsi que "Portugal é a Ordem do Templo até D. Manuel I e desde a origem" ${ }^{5}$. Cette tradition, restée vive ${ }^{6}$, a alimenté un substrat culturel qui a influencé, Portugais ou étrangers, bien des médiévistes, spécialistes du Temple et parfois remarquables connaisseurs de sa documentation. À sa façon, l'ouvrage le plus récent sur le sujet, Templários em Portugal. Homens de religião e de guerra, l'illustre: en conclusion, son auteure, Paula Pinto Costa, s'est interrogée pour savoir si l'ordre "em Portugal interpretava-se mais como uma instituição nacional ou como um ramo de uma organização internacional" hors de la péninsule Ibérique, cette alternative ne ferait pas sens. En France, en Angleterre ou en Italie, chacun est convaincu que le Temple, pour prêter écho à ma collègue de l'Universidade do Porto, "proporcionou-nos uma das mais antigas experiências de pendor global, de expressão internacional, em que a mobilidade de pessoas e a organização institucional superavam fronteiras". Au Portugal, la question n'est pas si simple ou, du moins, pour continuer avec l'auteure, "a resposta depende de muitas variáveis"'. Le Temple y aurait-il été différent, moins lié à la Terre sainte que dans le reste de l'Occident des $\mathrm{XII}^{\mathrm{e}}$ et XIII ${ }^{\mathrm{e}}$ siècles ? Si Paula Pinto Costa a relevé que, par son intermédiaire, "a Europa descobria formas de ampliar horizontes e de manter articulações, cada vez mais consolidadas, com espaços distantes" ${ }^{10}$, elle n'a rien dit de la façon dont cela s'opérait et, hormis dans le cas bien connu de Gualdim Pais ${ }^{11}$, les références de son livre aux voyages des frères ${ }^{12}$, à des envois de chevaux ou de responsions ${ }^{13}$, restent purement génériques et appuyées sur l'unique texte de la règle de l'ordre ${ }^{14}$. La province templière de Portugal, du fait "da sua gradual autonomização"15, aurait connu, à la fin du XIII e siècle, un "afastamento definitivo da Terra Santa" ${ }^{16}$. L'idée, ici, est des plus traditionnelles et, contre ce préjugé, une fois de plus revivifié, j'aimerais attirer l'attention sur un document riche et singulier, impliquant en 1282 Lourenço Martins, lieutenant du maître provincial du Temple au Portugal, dans un transport méditerranéen entre Barcelone et Acre, de façon à revenir ensuite et - peut-être - à mieux poser le vieux débat autour du caractère national si volontiers prêté à l'ordre au pays de Fernando Pessoa.

2 Dans l'occident hispanique, l'histoire institutionnelle du Temple reste en bonne partie à écrire, mais au Portugal, théâtre en la matière d'un intéressant renouveau historiographique depuis le début du $\mathrm{xxI}^{\mathrm{e}}$ siècle, le travail est plus avancé que pour le León et la Castille ${ }^{17}$. Au sein de l'ordre, ces trois espaces formèrent le plus souvent un seul ensemble, articulé cependant en fonction de la division des royaumes et confié à deux ou trois responsables dont les titulatures, jusqu'à l'aube du XIV siècle, ont varié18. Des deux côtés de la raia, la liste des maîtres provinciaux - pour leur garder ici une seule appellation - est loin d'être établie et, conscient de ce manque, j'avais convié Saul António Gomes en 2015, lors du VII Encontro sobre ordens militares, à étudier "os últimos mestres do Templo em Portugal". Lourenço Martins est l'un d'eux et, dans l'attente que mon collègue de l'Universidade de Coimbra, excellent connaisseur de la documentation de l'ordre et habile dans l'utilisation de la prosopographie, publie la réflexion qu'il n'avait pu alors finaliser ${ }^{19}$, il convient d'opérer à partir d'une information fragmentaire. Paula Pinto Costa, qui a travaillé à la synthétiser, a bien rappelé que le dignitaire, par deux fois, avait été placé à la tête des Templiers portugais, d'abord au début des années 1280 , puis, quelque dix plus tard, à l'aube de la décennie suivante ${ }^{20}$, mais jamais elle n'a 
indiqué qu'il voyagea outre-mer. À l'exemple de Gualdim Pais, engagé cinq ans en Orient au milieu du XII ${ }^{\mathrm{e}}$ siècle $^{21}$, des frères du royaume avaient pourtant l'habitude de traverser la Méditerranée ${ }^{22}$. Lourenço Martins, en 1282, fut de ceux-là: avant lui, Afonso Gomes, appelé aussi à devenir maître provincial ${ }^{23}$, avait été le compagnon du grandmaitre Thomas Bérard, à Acre en $1258^{24}$, et, à leur suite, plusieurs compatriotes étaient partis combattre en Orient, à l'instar d'André Gonçalves de Pombal, témoin de la chute d'Acre en $1291^{25}$, ou des trois chevaliers interrogés à Chypre en mai 1310, Estêvão, João et Lourenço, entrés au Temple, le premier, au début de la décennie 1290, et, pour les deux autres, en $1300^{26}$, tandis que Jacques de Molay projetait en Syrie une action militaire à laquelle Vasco Fernandes, le dernier supérieur de l'ordre au Portugal, s'était associé ${ }^{27}$.

3 À l'été 1282 , le transport de Lourenço Martins outre-mer ne doit donc pas étonner: il s'inscrivait dans une pratique relativement fréquente des Templiers portugais. Pourtant, jusqu'à mon étude récente sur Jacques de Molay, nul ne l'avait jamais mentionné et l'acte qui en porte trace, à l'Archivo de la Corona de Aragón, était demeuré inédit ${ }^{28}$. Le document, par ses aspects contractuels, avait bien éveillé l'attention d'historiens intéressés par l'insertion des marchands dans la logistique du Temple, Alan Forey d'abord ${ }^{29}$, puis Damien Carraz $^{30}$, mais ni l'un ni l'autre, quoi qu'excellents connaisseurs de l'ordre, n'avaient identifié ou même cité Lourenço Martins. Présenté comme le "lieutenant du maître provincial de Portugal" (tenens locum magistri milicie Templi in regno Portugalie), c'est pourtant lui qui est à l'origine de l'accord passé entre Ramon Marquet, citoyen de Barcelone, et Romeu Burguet, commandeur templier de Palau-solità ${ }^{31}$. Le $1^{\text {er }}$ avril 1282, les deux hommes se sont entendus en vue d'organiser le futur voyage (viaticum) du dignitaire lusitanien et de sa suite entre Barcelone et Acre. Celle-ci était composée de quatre frères du Temple, accompagnés de quarante-cinq à cinquante bêtes - entre chevaux et mules - ainsi que des écuyers et des victuailles leur correspondant. Ramon Marquet s'obligeait à tenir prête sa nef (navis) au $1^{\mathrm{er}}$ août et le départ, "salvo impedimenti Dei", aurait lieu avant le 15 du mois, au-delà duquel les Templiers portugais seraient fondés à réclamer le remboursement des frais encourus à Barcelone. Pour le voyage, le marchand s'engageait à réserver au dignitaire un emplacement sur le pont (platea de ponte) et à fournir des places adaptées (platee congruentes) aux autres frères, aux écuyers et aux animaux, en leur assurant toute l'eau nécessaire. Le prix du passage était fixé à un marc d'argent fin pour chaque Templier, soit quelque 233 grammes, et à 2,5 pour chaque bête et son écuyer, une somme représentant alors le huitième de la valeur d'un cheval en Aragon ${ }^{32}$. Des écuyers en plus grand nombre pourraient être embarqués, si Lourenço Martins le désirait, mais leur transport se ferait - sans que le contrat en donne le montant - au tarif prévu par la coutume maritime (nauleum consuetum).

Bien avant d'arriver à Barcelone, d'où il escomptait appareiller, Lourenço Martins s'est ainsi préoccupé de son passage outre-mer. Il l'a probablement fait du Portugal, s'inscrivant dans une pratique dont j'aimerais souligner combien elle apparait rodée. Les deux acteurs du contrat souscrit en son nom étaient l'un et l'autre dûment qualifiés. À Barcelone, ils étaient même, dans la première moitié des années 1280, des hommes en vue. Depuis le printemps 1281 au moins ${ }^{33}$, Romeu Burguet était à la tête de la commanderie de Palau-solità, dans le Vallès, dont dépendait à l'origine la maison templière de Barcelone ${ }^{34}$ : il y avait remplacé Ramon de Barberà ${ }^{35}$, appelé onze ans plus tard à faire partie du couvent de Jacques de Molay ${ }^{36}$, et, en 1282, c'est lui qui en transféra le siège dans le grand port catalan ${ }^{37}$, où il demeura en charge des affaires de 
l'ordre jusqu'en 1285, officiant même, en raison de sa compétence juridique, comme procureur de ses frères, à l'image du commandeur de Barberà, qu'il a représenté dans un litige avec la couronne portant sur le château d'ollers ${ }^{38}$. Ramon Marquet, quant à lui, avait plus de notoriété encore et, issu d'une famille engagée depuis la décennie 1240 dans le grand commerce ${ }^{39}$, il a commandé plusieurs vaisseaux lors de voyages au Levant, servant à l'occasion d'ambassadeur, notamment en Égypte ${ }^{40}$ : la confiance du roi Pierre III lui était acquise, qui l'amena à prendre part en 1282 à l'expédition contre Tunis et à remplir aux années suivantes des missions délicates, à Pise, où des marins catalans s'étaient révoltés, et à Majorque ${ }^{41}$, en association avec Berenguer Mallol, à qui Pere Mallol, cité dans l'acte du $1^{\mathrm{er}}$ avril $1282^{42}$, était certainement apparenté. Ensemble, Romeu Burguet et Ramon Marquet avaient déjà travaillé en 1281: au service du Temple, le marchand, sur sa nef, avait pris en charge du blé dont le grand-maître Guillaume de Beaujeu, à Acre, s'était déclaré satisfait du transport ${ }^{43}$. Lourenço Martins, dans son entreprise, ne pouvait donc choisir de meilleurs associés et, parce qu'il l'avait préparé au mieux, le voyage se fit apparemment sans encombre 44 ; le 12 janvier 1283 , le dignitaire portugais était de retour à Marseille, d'où il a prié Pierre III de lui adresser un sauf-conduit (guidaticum et conductus) pour les marins d'une nef du Temple, La Rose, avec laquelle il était sans doute revenu d'Acre ${ }^{45}$.

5 Tout un imaginaire, depuis le xIx ${ }^{e}$ siècle, unit les Templiers à l'Orient ${ }^{46}$, mais c'est de la relation entre les deux extrémités de la Méditerranée que les frères, à l'instar des Hospitaliers et des Teutoniques, tiraient la force et l'originalité de leur projet ${ }^{47}$. Le fait régional, dans l'analyse, est donc crucial à considérer ${ }^{48}$, mais il ne prend sens que rapporté au tout et, pour user des mots d'Alain Demurger, "c'est moins en termes d'implantation locale qu'en termes de mission qu'il faut étudier ces ordres ou - pour le dire autrement et plus justement - c'est en fonction de leur mission qu'il faut étudier leur implantation locale et leurs activités à "l'arrière" 49 . Au Temple, cela vaut jusqu'à la fin de son histoire ${ }^{50}$, même si bien des polygraphes, à l'exemple de Laurent Dailliez, ont imaginé que l'ordre se serait progressivement scindé en deux ${ }^{51}$. Les historiens, trop souvent, ont épousé un tel préjugé dont au Portugal aujourd'hui, plus que nulle part ailleurs, on peut observer la prégnance. Luís Filipe Oliveira, dans un remarquable travail historiographique, joliment intitulé "une histoire à rebours", achève cependant de déconstruire pareil topos et, grâce à son érudition sûre, il en a révélé la genèse $\mathrm{e}^{52}$. Kristjan Toomaspoeg, en 2012, avait certes signalé que le Temple, de longue date, était tenu au Portugal pour la préfiguration de l'ordre du Christ et, pour cette raison, lié intrinsèquement aux rois et au royaume $\mathrm{e}^{53}$, mais il revient à mon collègue de l'Universidade do Algarve d'avoir mis au jour la formation historique de ce préjugé, créé juste après l'affaire, devenu au $\mathrm{XvII}^{\mathrm{e}}$ siècle "une espèce de vérité officielle et définitive" et transformé désormais en un acquis relevant "pratiquement du sens commun (quase ao nível do senso comum)" ${ }^{54}$. Les trois thèses de doctorat, partiellement redondantes ${ }^{55}$, consacrées au Temple dans la première décennie du $\mathrm{xxI}^{\mathrm{e}}$ siècle ont chacune donné dans le panneau ${ }^{56}$, que bien des spécialistes portugais, de Mário Farelo à Paula Pinto Costa ${ }^{57}$, en passant par Saul António Gomes - pourtant probablement le plus sûr -, n'ont pas su éviter ${ }^{58}$, faisant invariablement état d'un ordre qui, au bord du Tage, se serait précocement nationalisé, en se détournant de l'Orient pour se concentrer sur la Reconquête et le service du roi.

6 En dehors même des milieux templaristes, qui - je l'ai signalé - ne renâclent pas devant l'exagération, la lecture nationale de l'histoire de l'ordre est largement partagée à 
l'échelle du Portugal. Elle a toutefois été sévèrement critiquée depuis une quinzaine d'années par Luís Filipe Oliveira ${ }^{59}$; Kristjan Toomaspoeg, qui l'a rejoint, y a même perçu "un problème conceptuel" ${ }^{60}$, dénonçant "un obstacle de nature idéologique" ${ }^{61}$. Les sources, en effet, ne permettent pas de valider la déconnexion de la province portugaise du Temple avec l'Orient. Celles qui insistent sur le lien, certes, sont rares et nulle part ou presque, dans la documentation conservée, il n'est fait état des responsions, ces envois à destination de la Terre sainte représentant plutôt le dixième que le tiers des rentes de chaque maison ${ }^{62}$. Opérés en espèces comme en nature vivres, armes, montures ou vêtements ${ }^{63}$-, ces transferts étaient pourtant au cœur de la logistique templière ${ }^{64}$. Qu'inférer de l'absence de traces qui est la leur au Portugal ? Estce qu'ils n'y auraient pas existé, contrairement au reste de l'Occident? Partout, en réalité, les responsions filtrent difficilement des sources ${ }^{65}$ : le constat que, vingt ans en arrière, j'avais réalisé pour la Castille ${ }^{66}$, qui pourrait à tort être tenue pour éloignée de l'Orient, vaut aussi pour la Provence ou l'Italie du Nord-Ouest, aux connexions indubitables ${ }^{67}$. La situation documentaire du Temple au Portugal n'a donc rien de spécifique et le nombre minime des références tient sans doute à ce que la lecture nationale de l'ordre, très tôt, a conditionné les pratiques de conservation archivistique ${ }^{68}$. Gualdim Pais, le célèbre maitre provincial de la seconde moitié du XII ${ }^{\mathrm{e}}$ siècle, n'est donc pas l'unique trait d'union entre les deux extrémités du monde méditerranéen. Dès les années 1120 , à Soure et, peut-être, près de Braga ${ }^{69}$, les premières donations au Temple avaient été faites pour le service de la Terre sainte ${ }^{70}$. Les autorités centrales de l'institution ne se sont jamais détournées du Portugal et, si le voyage prévu par le grand-maître Arnau de Torroja ${ }^{71}$, à l'automne 1184, a été interrompu par la mort ${ }^{72}$, elles ont été sollicitées par les frères locaux en 1231, puis en $1272^{73}$, l'année où Francon de Bort, décrit comme "geeral visitador", ramena de mission cinq cents marcs d'argent $^{74}$. Dix ans plus tard, à l'été 1282 , Lourenço Martins, lieutenant du maître provincial, quittait Barcelone avec quatre frères et un nombre important d'écuyers et de bêtes, démontrant que les Templiers portugais, loin de se cantonner au royaume, avaient Acre au cœur.

7 Eu égard à de tels liens, trop souvent tus par l'historiographie, la requête adressée le 23 mai 1307 par le Templier catalan Pere de Santjust, alors commandeur d'Alfambra, à Jacques de Molay afin qu'il franchisse les Pyrénées et vienne jusqu'en Castille et au Portugal prend tout son sens ${ }^{75}$. Pourtant, que je sache, cette lettre, publiée au début du $\mathrm{Xx}^{\mathrm{e}}$ siècle par Heinrich Finke sur la base d'un original conservé là encore à l'Archivo de la Corona de Aragón ${ }^{76}$, dont il a contribué à réorganiser les fonds intéressant le Temple $^{77}$, n'a jamais été étudiée par les chercheurs issus de l'Occident hispanique. Exceptionnellement bien connu du fait que subsiste une cinquantaine de missives qu'il a écrites ou reçues ${ }^{78}$, Pere de Santjust avait avec Jacques de Molay une relation étroite dont l'origine remontait probablement au siège $\mathrm{d}^{\prime} A \mathrm{Acre}^{79}$, où le frère catalan fut blessée ${ }^{80}$. Tenus à distance par la mer Méditerranée, même s'ils se sont vus en Catalogne et à Chypre $^{81}$, les deux hommes avaient l'habitude d'échanger sur l'état du Temple: le grand-maître se fiait à son ami, dont en 1306, avant d'embarquer pour l'Occident, il a recherché le conseil sur la croisade et, peut-être, l'union des ordres militaires ${ }^{82}$. Rentré de Chypre, Pere de Santjust a activé ses réseaux dans la péninsule Ibérique et, au printemps 1307, des frères de Castille et de Portugal lui ont fait savoir, par leurs courriers, que la venue de Jacques de Molay jusqu'à eux, comme en Catalogne, "seria molt profitosa" ${ }^{\prime 3}$. Le Temple était alors confronté à une situation difficile. Depuis $1305 \mathrm{au}$ moins, Denis I ${ }^{\text {er }}$ œuvrait à retrouver les droits de la couronne portugaise ${ }^{84}$, et, le 6 août 
1306, l'ordre fut contraint à un échange où il cédait un bien-fonds à Santarém, des droits de péage à Coïmbre et de patronage à Trancoso pour Vila de Rei et Ferreira do Zêzere ${ }^{85}$. La pression royale, étudiée par Mário Farelo ${ }^{86}$, est à mon sens la raison de l'appel lancé à Jacques de Molay que le maître provincial, Vasco Fernandes, réitéra le 18 août 1307, quand des possessions vitales pour l'institution, Soure, Pombal, Ega et Redinha, d'un côté, Idanha-a-Velha et Salvaterra, de l'autre, furent revendiquées par le pouvoir monarchique ${ }^{87}$. À la veille du déclenchement de l'affaire, les frères portugais espéraient que le grand-maitre intervînt directement, informés sans doute que dans la Castille voisine - où, malgré le sentiment dominant ${ }^{88}$, la lecture nationale de l'histoire du Temple est à mon avis tout aussi irrecevable ${ }^{89}$ - des échanges avaient été récemment consentis depuis le couvent de Chypre ${ }^{90}$, avec lequel le lien restait essentiel.

Le Temple, au Portugal, n'a jamais été une institution nationale. En affirmant l'inverse, toute une tradition littéraire et philosophique, illustrée par des auteurs majeurs, a méconnu le fait que, dans l'histoire, les héritiers d'Hugues de Payns, directs ou non, ont créé, pour reprendre les mots de Karl Borchardt, "les premiers ordres religieux véritablement centralisés" ${ }^{91}$. Certes, ni Fernando Pessoa, ni ses précurseurs ou ses suiveurs n'avaient à entrer dans une telle analyse, mais l'innovation eut une portée considérable et, adoptée dès le XII siècle par les Prémontrés et développée ensuite par les Mendiants ${ }^{92}$, elle a joué un rôle crucial dans la naissance du principe territorial d'administration dont notre monde participe encore largement ${ }^{93}$. Bien des historiens, le cas échéant remarquables, n'en disent rien ${ }^{94}$. Le Portugal n'échappe pas à la règle et, jusqu'au début du $\mathrm{xxI}^{\mathrm{e}}$ siècle, les spécialistes, lorsqu'ils abordaient le Temple, en procuraient, à l'intérieur des limites du royaume, une lecture nationale, influencée consciemment ou non - par cette si particulière tradition locale de pensée. Grâce aux travaux de Luís Filipe Oliveira notamment, la situation, aujourd'hui, s'est quelque peu infléchie. Le Temple est sans doute moins envisagé en termes strictement lusitaniens qu'il y a quinze ans, mais - hormis dans ses origines - il reste trop peu lié à la Terre sainte. La province portugaise de l'ordre passe en effet pour s'être détachée de l'Orient latin à la faveur d'une "gradual autonomização" que Paula Pinto Costa, dans le dernier livre de référence sur le sujet, vient encore de mettre en exergue. L'idée, pour une bonne part, tient à mon sens du mythe. L'ordre, jusqu'à la fin, est demeuré un. Au Portugal, comme ailleurs en Occident, les monarques, soucieux d'affirmer leur souveraineté, ont à partir du milieu du XIII ${ }^{\mathrm{e}}$ siècle suscité davantage d'obstacles aux Templiers dans leurs circulations méditerranéennes. Si Alan Forey, qui a étudié ces interférences royales, ne les a pas jugées dirimantes, estimant, de façon exagérée, que l'impécuniosité des frères était plus gênante ${ }^{95}$, Helen Nicholson a souligné, dans le cas de l'Angleterre, la force qu'elles ont pu avoir ${ }^{96}$. À la charnière des XIII et XIV siècles, Denis $I^{\text {er }}$ a parfois agi vigoureusement contre le Temple, mais les autorités de ce dernier, Jacques de Molay en tête, ont résisté aux atteintes juridictionnelles du roi avec résolution. Périphériques par rapport à l'Italie méridionale ou à la Provence, la province portugaise de l'ordre n'a pas été dissociée du centre, représenté par le couvent de Chypre, et sans doute lui fut-elle même mieux liée - au moins dans l'intention ${ }^{97}-$, comme l'ont été les régions lointaines du Saint-Empire, où, jusqu'à l'est de l'Elbe, les structures templières furent organisées avec toujours plus de précision de manière à ce que, malgré d'éventuels conflits ${ }^{98}$, elles soient plus complètement associées au front et à l'effort commun engagé pour recouvrer la Terre sainte ${ }^{99}$. Au service de l'Orient latin, le Temple a donc mobilisé hommes et ressources jusqu'au bout, jusqu'à cette fin, imprévue et imprévisible, précipitée en 1307 par l'affaire, et il l'a fait 
au Portugal comme ailleurs. L'Aragon, certes, est aujourd'hui l'unique province pour laquelle on puisse, tant soit peu, quantifier l'effort accompli ${ }^{100}$, mais les espaces en apparence plus périphériques, souvent éloignés du regard des historiens, ne sont pas forcément en reste et d'Angleterre ${ }^{101}$, sur la base de la documentation du procès ${ }^{102}$, comme de Castille ou du Portugal ${ }^{103}$, on a trace de transferts opérés à destination du Levant. Les mieux connaître est un défi pour la recherche qui suppose d'abord de ne pas les nier a priori; au Portugal, cela exige de ne plus traiter du Temple dans une optique strictement lusitanienne et de le lier - malgré les difficultés des sources - à l'Orient latin. Connecter mieux et davantage est un projet toujours à entreprendre, dans lequel j'ai tâché de m'inscrire de longue date ${ }^{104}$, en sollicitant des fonds d'archives et, plus largement, une documentation qu'on ne peut réduire à une dimension nationale, quelle qu'elle soit ${ }^{105}$; le mettre et le remettre sur le chantier est une nécessité, à laquelle aidera, en termes épistémologiques, l'História global de Portugal ${ }^{106}$, conçue sur le modèle d'Histoire mondiale de la France ${ }^{107}$, dont la publication, à l'automne 2020, est attendue à l'heure où je reprends une dernière fois ces lignes qui, à leur échelle, s'avèreront, je l'espère, utiles elles aussi.

\section{BIBLIOGRAPHIE}

Sources

BARROCA, Mário Jorge - Epigrafia medieval portuguesa (862-1422). Lisboa: Fundação Calouste Gulbenkian, 2000, 3 vol.

CINGOLANI, Stefano - Diplomatari de Pere el Gran. Barcelona: Fundació Noguera, 2011-2015, 2 vol. CONDE y DELGADO DE MOLINA, Rafael; PUJADES I BATALLER, Ramón José - "Epistolario de Jacques de Molay y cartas manuscritas de los Templarios". in ALVAR EZQUERRA, Carlos et. al. (eds.) - Secretum Templi. Valencia: Grial, 2005, t. III, pp. 103-165.

CURzon, Henri de - La Règle du Temple. Paris: Société de l'Histoire de France, 1886.

DELAVILLE LE ROULX, Joseph - Documents concernant les Templiers extraits des archives de Malte. Paris: Plon, 1882.

FERNANDEZ RUIZ, Raquel del Carmen - Colección diplomática del monasterio de Santo Domingo de Benavente (1228-1390). Benavente: Centro de Estudios Benaventanos Ledo del Pozo, 2000.

FOREY, Alan - "Letters of the Last Two Templar Masters". Nottingham Medieval Studies 45 (2001), pp. 145-171.

GOMES, Saul António - Pombal medieval e quinhentista. Documentos para a sua história. Leiria: Centro do Património de Estremadura, 2010.

NICHOLSON, Helen -The Proceedings against the Templars in the British Isles. Farnham: Ashgate, 2011, 2 vol.

PESSOA, Fernando - Escritos íntimos. Cartas e páginas autobiográficas. Éd. António Quadros. Mem Martins: Pub. Europa América, 1986. 
SÁ NOGUEIRA, Bernardo de - O Livro das Lezírias d'el-rei Dom Dinis. Lisboa: Centro de História da Universidade de Lisboa, 2003.

VENTURA, Leontina; RESENDE DE OLIVEIRA, António - Chancelaria de D. Afonso III. Livro I. Coimbra: Imprensa da Universidade de Coimbra, 2006, 2 vol.

“Vita Martini Sauriensis". in NASCIMENTO, Aires A. - Hagiografia de Santa Cruz de Coimbra. Lisboa: Colibri, 1998, pp. 223-240.

\section{Études}

ADRIÃo, Vítor Manuel - Portugal templário: Vida e obra da Ordem do Templo. Lisboa: Via Occidentalis, 2007.

AYALA MARTínEZ, Carlos de - "Las órdenes militares y los procesos de afirmación monárquica en Castilla y Portugal (1250-1350)". in FONSECA, Luís Adão da (ed.) - As relações de fronteira no século de Alcanices. Actas das IV Jornadas luso-espanholas de história medieval. Porto: Imprensa da Universidade do Porto, 1998, t. II, pp. 1279-1312.

AYALA MARTínEZ, Carlos de - "Frontera castellano-leonesa y órdenes militares. Problemas de jurisdicción (siglos XII-XIII)”. in ÁLVAREZ PALENZUELA, Vicente -Jornadas de cultura hispano-portuguesa. Madrid: Universidad Autónoma de Madrid, 1999, pp. 51-92.

AYALA MARTíNEZ, Carlos de - "Fernando III y las órdenes militares". in PEÑA SOLAR, Juan Ignacio de la - Fernando III y su tiempo (1201-1252). Congreso de estudios medievales. Ávila: Fundación SánchezAlbornoz, 2003, pp. 67-101.

BAGNI, Giampiero - “The Sarcophagus of Templar Master Arnau de Torroja in Verona? Sources and Scientific Analysis". Crusades 17 (2018), pp. 31-38.

BARROCA, Mário Jorge - “A Ordem do Templo e a arquitectura militar portuguesa do século XII". Portugalia 17-18 (1996-1997), pp. 171-209.

BELLOMO, Elena - The Templar Order in the North-West Italy (1142-c. 1330), Leyde-Boston, Brill, 2008.

BELLOMO, Elena - “Templari, Oriente, crociata: percorsi di ricerca in Italia settentrionale”. in FERNANDES, Isabel Cristina F. (ed.) - As ordens militares. Freires, guerreiros, cavaleiros. Actas do VI Encontro sobre ordens militares. Palmela: Município de Palmela-GEsOS, 2012, t. II, pp. 799-822.

BENSCH, Stephen - Barcelona and its Rulers, 1096-1291. Cambridge: Cambridge University Press, 2002. BERTHEL, Alex - “Die Templer im Gebiet östlich der Elbe zur Aufhebung des Ordens (1312)”. Sacra Militia. Rivista di storia degli ordini militari 1 (2000), pp. 13-54.

BORCHARDT, Karl - “The Templars in Central Europe”. in HUNYADI, Zsolt; LASZLOVSKY, József (eds.) The Crusades and the Military Orders. Expanding the Frontiers of Medieval Latin Christianity. Budapest: Central European University, 2001, pp. 233-244.

BORCHARDT, Karl - “The Military-Religious Orders: A Medieval “School for Administrators"?". in EDBURY, Peter (ed.) - The Military Orders. Vol. 5. Politics and Power. Farnham: Ashgate, 2012, pp. 3-20.

BORCHARDT, Karl - "The Templars and the Thirteenth-Century Colonisation in Eastern Central Europe”. in BAUDIN, Arnaud; BRUNEL, Ghislain; DOHRMANN, Nicolas (eds.) - L'Économie templière en Occident. Patrimoines, commerce, finances. Langres: Guéniot, 2013, pp. 415-452.

BOUCHERON, Patrick (ed.) - Histoire mondiale de la France. Paris: Seuil, 2017. 
CARRAZ, Damien - L'Ordre du Temple dans la basse vallée du Rhône (1124-1312). Ordres militaires, croisades et sociétés méridionales. Lyon: Presses universitaires de Lyon, 2005 (rééd. 2020).

CARRAZ, Damien - “Templiers et négociants méditerranéens: des intérêts convergents”. Histoire et images médiévales 46 (2012), pp. 25-32.

CLAVERIE, Pierre-Vincent - "Contra soldanum de Coine ou la contribution des Templiers portugais à la défense de la Syrie franque". in FERNANDES, Isabel Cristina F. (ed.) - As ordens militares e as ordens de cavalaria entre o Ocidente e o Oriente. Actas do V Encontro sobre ordens militares. Palmela: Câmara Municipal de Palmela-GEsOS, 2009, pp. 399-412.

costA, Paula Pinto - "Templários no condado portucalense antes do reconhecimento formal da ordem: O caso de Braga no início do século XII". Revista da Faculdade de Letras do Porto. Ciências e Técnicas do Património 12 (2013), pp. 231-243.

costA, Paula Pinto - Templários em Portugal. Homens de religião e de guerra. Barcarena: Manuscrito, 2019.

DAILLIEZ, Laurent - Jacques de Molay, dernier maître du Temple. Paris: Dumas, 1974.

DALARUN, Jacques - Gouverner c'est servir. Essai de démocratie médiévale. Paris: Alma, 2012.

DEMURGER, Alain - Les Templiers. Une chevalerie chrétienne au Moyen Âge. Paris: Seuil, 2005.

DEMURGER, Alain - "L'étude des ordres religieux-militaires en France: la fin de la marginalité ? Introduction au dossier". Cahiers de recherche médiévale. A Journal of Medieval Studies 15 (2008), pp. 169-173.

ELM, Kaspar - "Gli ordini militari: un ceto di vita religiosa fra universalismo e particolarismo". in MARCO, Maria de; TOMMASI, Francesco (eds.) - Militia Sacra. Gli ordini militari tra Europa e Terrasanta. Pérouse: Società Editrice San Bevignate, 1994, pp. 9-28.

ELM, Kaspar - "Die Ordines militares. Ein Ordenszötus zwischen Einheit und Vielfalt". in HUNYADI, Zsolt; LASZLOVSKY, József (eds.) - The Crusades and the Military Orders. Expanding the Frontiers of Medieval Latin Christianity. Budapest: Central European University, 2001, pp. 351-377.

FARELO, Mário - "Pro defensione iuris regis. Les relations entre la Couronne portugaise et le pape Clément V à la lumière du procès des Templiers". in CARREIRAS, José Albuquerque (ed.) - A Extinção da Ordem do Templo. Tomar: Instituto Politécnico de Tomar, 2012, pp. 63-109.

FERNANDES, Maria Cristina - A Ordem do Templo em Portugal das origens à extinção. Porto: Universidade do Porto, 2009. Thèse de doctorat.

FINKE, Heinrich - Papsttum und Untergang des Templerordens. Münster: Aschendorff, 1907, 2 vol. FIOLHAIS, Carlos; FRANCO, José Eduardo; PAIVA, José Pedro (ed.) - História global de Portugal. Lisboa: Círculo de Leitores, 2020.

FOREY, Alan - The Templars in the Corona de Aragón. Oxford: Oxford University Press, 1973.

FOREY, Alan - "The Career of a Templar: Peter of St Just”. in HOUSLEY, Norman (ed.) -Knighthoods of Christ. Essays on the History of the Crusades and the Knights Templar, Presented to Malcolm Barber. Aldershot: Ashgate, 2007, pp. 183-194.

FOREY, Alan - "Aragonese Templars in the Holy Land and in Cyprus in the Late Thirteenth and Early Fourteenth Centuries". in FERNANDES, Isabel Cristina F. (ed.) - As ordens militares e as ordens de cavalaria entre o Ocidente e o Oriente. Actas do V Encontro sobre ordens militares. Palmela: Câmara Municipal de Palmela-GEsOS, 2009, pp. 451-461. 
FOREY, Alan - "Notes on Templar Personnel and Government at the Turn of the Thirteenth and Fourteenth Centuries”. Journal of Medieval History 35 (2009), pp. 150-170.

FOREY, Alan - "Royal and Papal Interference in Dispatch of Supplies to the East by the Military Orders in the Later Thirteenth Century". in EDBURY, Peter (ed.) - The Military Orders. Vol. 5: Politics and Power. Farnham: Ashgate, 2012, pp. 95-102.

FUGUET SANS, Joan - "La casa del Palau del Temple de Barcelona”. Locus amœnus 7 (2004), pp. 99-109.

GOMES, Saul António - “A presença das ordens militares na região de Leiria (séculos XII-XIV)”. in FERNANDES, Isabel Cristina F.; PACHECO, Paulo (ed.) - As ordens militares em Portugal e no Sul da Europa. Lisboa-Palmela: Colibri-Câmara Municipal de Palmela, 1997, pp. 143-204.

GOMES, Saul António - “Observações em torno das Chancelarias das Ordens Militares em Portugal na Idade Média”. in FERNANDES, Isabel Cristina F. (ed.) - As ordens militares e as ordens de cavalaria na construção do mundo ocidental. Actas do IV Encontro sobre ordens militares. Palmela: Município de Palmela-GEsOS, 2009, pp. 111-167.

GOMES, Saul António - “A Extinção da Ordem do Templo em Portugal”. Revista da História da Sociedade e da Cultura 11 (2011), pp. 75-116.

GOMES, Saul António - “D. Gualdim Pais (c. 1118/20-1195)”. População e Sociedade 23 (2015), pp. 11-23.

GUZzo, Cristian - "Milites Templi Hierosolimitani in Regno Siciliae. Vecchi documenti, nuove acquisizioni”. in GUzzo, Cristian (ed.) - I Templari nell'Italia centro-meridionale. Storia ed architettura. Tuscania: Penne e Papiri, 2008, pp. 57-132.

JOSSERAND, Philippe - “Entre Orient et Occident: l'ordre du Temple dans le contexte castillan du règne d'Alphonse X”. Alcanate. Revista de Estudios Alfonsíes 2 (2000-2001), pp. 131-150.

JOSSERAND, Philippe - Église et pouvoir dans la péninsule Ibérique. Les ordres militaires dans le royaume de Castille (1252-1369). Madrid: Casa de Velázquez, 2004.

JOSSERAND, Philippe - "Et succurere Terre sancte pro posse: les Templiers castillans et la défense de l'Orient latin au tournant des XIII et XIV ${ }^{\mathrm{e}}$ siècles". Cahiers de recherches médiévales. A Journal of Medieval Studies, 15 (2008), pp. 217-235.

JOSSERAND, Philippe - "Entre dos frentes: aproximación a las empresas militares de los Templarios del Occidente peninsular (siglos XII-XIV)". in RODRÍGUEZ DE LA PEÑA, Alejandro (ed.) - Hacedores de frontera. Estudios sobre el contexto social de la frontera en la España medieval. Madrid: CEU Ediciones, 2009, pp. 179-201.

JOSSERAND, Philippe -“De l'arrière au front: regards sur la logistique des ordres militaires au Moyen Âge". in FERNANDES, Isabel Cristina F. (ed.) - As ordens militares. Freires, guerreiros, cavaleiros. Actas do VI Encontro sobre ordens militares. Palmela: Município de Palmela-GEsOS, 2012, t. II, pp. 683-703.

JOSSERAND, Philippe - "Troubles and Tensions before the Trial: the Last Years of the Castilian Templar Province". in EDBURY, Peter (ed.) - The Military Orders, vol. 5: Politics and Power. Farnham: Ashgate, 2012, pp. 363-375.

JOSSERAND, Philippe - "Jacques de Molay acteur hispanique? Au carrefour des représentations, de la mémoire et de l'histoire”. in AYALA MARTÍNEZ, Carlos; PALACIOS ONTALVA, Santiago; Ríos SALOMA, Martin - Guerra santa y cruzada en el estrecho: el Occidente peninsular en la primera mitad del siglo XIV. Madrid: Sílex, 2016, pp. 443-459. 
JOSSERAND, Philippe - "Editing Templar Charters in the Iberian Peninsula at the Beginning of the Twenty-First Century". in BORCHARDT, Karl, et. al. (ed.) - The Templars and their Sources. OxonNew York: Routledge, 2017, pp. 96-105.

JOSSERAND, Philippe -“Jacques de Molay en terres ibériques: avatars d'une représentation”. in FERNANDES, Isabel Cristina F. (ed.) - Entre Deus e o rei. 0 mundo das ordens militares. Palmela: Município de Palmela-GEsOS, 2018, t. II, pp. 573-583.

JOSSERAND, Philippe - Jacques de Molay. Le dernier grand-maître des Templiers. Paris: Les Belles Lettres, 2019.

JOSSERAND, Philippe; BERIOU, Nicole (ed.) - Prier et combattre. Dictionnaire européen des ordres militaires au Moyen Âge. Paris: Fayard, 2009.

MARTíNEZ DíEZ, Gonzalo - Los Templarios en la Corona de Castilla. Burgos: La Olmeda, 1993.

MELVILLE, Gert - "La recherche sur les ordres religieux en Allemagne. Chemins parcourus et nouveaux horizons". Cahiers de civilisation médiévale 49 (2006), pp. 163-174.

NICHOLSON, Helen - "International Mobility versus the Needs of the Realm: the Templars and Hospitallers in the British Isles in the Thirteenth and Fourteenth Centuries". in BURGTORF, Jochen; NICHOLSON, Helen (ed.) - International Mobility in the Military Orders (Twelfth to Fifteenth Centuries). Cardiff: University of Wales Press, 2006, pp. 87-101.

NICHOLson, Helen - "How Secret was the Templar Admission Ceremony? Evidence from the Proceedings in Britain and Ireland". in SAMMARCO, Sergio - Conmilitones Christi. Miscellanea di studi per il Centro Italiano di Documentazione sull'Ordine del Tempio. Rome: Lisanti, 2016, pp. 85-98. OLIVEIRA, Luís Filipe - “Ordem militar do Templo". in VASCONCELOS E SOUSA, Bernardo (ed.) Ordens religiosas em Portugal. Das origens a Trento. Guia Histórico. Lisboa: Livros Horizonte, 2005, pp. 461-465.

OLIVEIRA, Luís Filipe - "The Military Orders in the Twelfth-Fourteenth Centuries". in MATTOSO, José (ed.) - The Historiography of Medieval Portugal, c. 1950-2010. Lisboa: Instituto de Estudos Medievais, 2011, pp. 425-439.

OLIVEIRA, Luís Filipe - "Uma História às Avessas. A Historiografia do Templo em Portugal”. in FERNANDES, Isabel Cristina F. (ed.) - Entre Deus e o rei. 0 mundo das ordens militares. Palmela: Município de Palmela-GEsOS, 2018, t. II, pp. 671-684.

PAGAROLAS I SABATÉ, Laureà - Els Templers de les terres de l'Ebre (Tortosa). De Jaume I fins a l'abolició de l'orde (1213-1312). Tarragona: Diputació de Tarragona, 1999, 2 vol.

PARASCHI, André J. - História dos Templários em Portugal: a Fundação e os Mestres. Lisboa: Sol Invictus, 1990.

PIZARRO, José Augusto de Sotto Mayor - D. Dinis. Lisboa: Círculo de Leitores, 2005.

REFICE, Paola - "Le epigrafi di Tomar e di Almourol: elementi per lo studio delle fondazioni templari portoghesi". in VITI, Goffredo; CADEI, Antonio; ASCANI, Valerio (ed.) - Monaci in armi. L'architettura sacra dei Templari attraverso il Mediterraneo. Florence: Casa Editrice Certosa Cultura, 1995, pp. 175-186.

RICHARD, Jean - "Le comté de Tripoli dans les chartes du fonds des Porcellet". Bibliothèque de l'École des chartes 130 (1972), pp. 339-382. 
RILEY-SMITH, Jonathan - "Towards a History of Military-Religious Orders". in BORCHARDT, Karl, et. al. (ed.) - The Hospitallers, the Mediterranean and Europe. Festschrift for Anthony Luttrell. Aldershot: Ashgate, 2007, pp. 269-284.

SANS I TRAVÉ, Josep Maria - Els Templers catalans. De la rosa a la creu. Lleida: Pagès, 1996.

SANS I TRAVÉ, Josep Maria - Arnau de Torroja: un Català mestre major de l'orde del Temple (1118/1120 ?-1184). Barcelone: Reial Acadèmia de Bones Lletres de Barcelona, 2006.

SARNOWSKY, Jürgen - "Mendicants, Military Orders, and Regionalism”. in SARNOWSKT, Jürgen

(ed.) - Mendicants, Military Orders, and Regionalism in Medieval Europe. Aldershot: Ashgate, 1999, pp. 283-288.

SCHOTTMÜLLER, Konrad - Der Untergang des Templer-Ordens mit urkundlichen und kritischen Beiträgen. Berlin: Mittler und Sohn, 1887, 2 vol.

SILVA, Luiz Ademir da - "Da cruzada à demanda. A tradição épica da ordem dos Templários na Baixa Idade Média portuguesa (séculos XII-XIV)". Goiânia: Universidade Federal de Goiás, 2008. Thèse de doctorat.

SOLDEVILA, Ferran - L'almiral Ramon Marquet. Barcelone: Barcino, 1953.

STAHULJAK, Zrinka - Pornographic Archaeology: Medicine, Medievalism, and the Invention of the French Nation. Philadelphie: University of Pennsylvania Press, 2013. Trad. fr. de Laurent Bury L'Archéologie pornographique. Médecine, Moyen Âge et histoire de France. Rennes: Presses universitaires de Rennes, 2018.

TELMO, António - História secreta de Portugal. Lisboa: Vega, 1977.

TOOMASPOEG, Kristjan - "Historiographie de l'ordre du Temple au Portugal: status quastionis". in CARREIRAS, José Albuquerque; VAIRO, Giulia Rossio (ed.) - I Colóquio internacional. Cister, os Templários e a ordem de Cristo. Tomar: Instituto Politécnico de Tomar, 2012, pp. 171-191.

TOOMASPOEg, Kristjan - "L'ordre du Temple en Occident et au Portugal”. in CARREIRAS, José Albuquerque (ed.) - A Extinção da Ordem do Templo. Tomar: Instituto Politécnico de Tomar, 2012, pp. 17-61.

VALENTE, José - "Soldiers and Settlers. The Knights Templar in Portugal, 1128-1319". Santa Barbara: University of California, 2002. Thèse de doctorat.

VOGEL, Christian - "Die Templer in Mitteleuropa und ihre Organisationsstrukturen". in BORCHARDT, Karl; JAN, Libor (ed.) - Die geistlichen Ritterorden in Mitteleuropa Mittelalter. Brno: Matice moravská, 2011, pp. 157-170.

\section{ANNEXES}

$1282,1^{\mathrm{er}}$ avril

Ramon Marquet, citoyen de Barcelone, et Romeu Burguet, commandeur templier de Palau-solità, passent un accord en vue du transport de Lourenço Martins, lieutenant du maître provincial de Portugal, de Barcelone à Acre. Ce dernier, avec quatre frères et quarante-cinq à cinquante bêtes, accompagnées des écuyers et des victuailles leur correspondant, promet d'embarquer le premier jour d'août sur le navire qui, dûment préparé, attendra au port. La traversée lui coûtera un marc d'argent pour chaque frère et deux marcs et demi pour chaque bête et son écuyer, sachant que des écuyers en plus 
grand nombre pourront être acheminés au tarif ordinairement prévu par la coutume maritime.

A - Aragón, Archivo de la Corona de Aragón, Cancelleria, Pergamins Pere II*, 292.

Éd. : JOSSERAND, Philippe - Jacques de Molay. Le dernier grand-maître des Templiers ..., 2019, p. 451-453, doc. 3.

In Dei nomine. Sit omnibus notum quod ego Raimundus Marcheti, civis Barchinone, convenio et promito per firmam stipulacionem vobis fratri Romeo Burgeti, comendatori domus de Palacio ordinis milicie Templi, presenti et stipulanti nomine fratris Laurencii Martiniz, tenentis locum magistri milicie Templi in regno Portugalie, quod defferam in navi mea quam de presenti facio de Barchinona apud Acon predictum fratrem Laurencium cum quatuor fratribus et de quadraginta quinque ad quinquaginta bestias sive equitaturas, inter equos et bestias mulares, cum suis scutiferis et victualibus, prout consuetum est. Promito eciam vobis nomine dicti fratris Laurencii quod predicta navis fuerit expedita, facta et bene preparata de marinariis et omnibus suis exarsiis et apparatibus in Dom(...) introuitu primi uenturi mensis augusti, ita quod tunc dicta navis faciet velum, Domino concedente, pro dicto viatico faciendo. Ita etiam quod dictus frater Laurencius cum quatuor fratribus et bestiis predictis, cum suis scutiferis et victualibus, sint tunc in Barchinona preparati pro dicto viatico faciendo. Et si forte, quod absit, dicta navis non fuerit tunc preparata et expedita pro dicto viatico faciendo et non recesserit de Barchinona usque ad primum venturum festu sancte Marie augusti per culpa mea, aportet (...) dictos fratres et bestias cum scutiferis suis in Barchinona a dicto festo in antea, convenio et promito per firmam stipulacionem vobis nomine dicti fratris Laurencii quod restituam dicto fratri Laurencio incontinenti cum $a b$ eo vel suis fuero requisitus omnes expensas et missiones quas oporteret ipsum facere in Barchinona in victualibus sui et familie sue et predictarum bestiarum a dicto festo sancte Marie augusti in antea, salvo impedimenti Dei. Et si forte etiam dictus frater Laurencius voluerit tunc mitere in dicta navi alios scutiferos ultra illos qui servient predictis bestiis, promito ipsos portare ad nauleum consuetum. Promito etiam vobis nomine dicti fratris Laurencii quod dabo ipsi fratre Laurencio plateam de ponte et aliis fratribus et scutiferis atque bestiis sive equitaturiis plateas congruentes et aquam in toto dicto viatico. Et obligo eidem fratri Laurencio, absenti, et vobis dicto comendatori, presenti et stipulanti nomine ipsius, propter hoc omnia bona mea, mobilia et immobilia, habita et habenda, renuncians quantum ad hec ex certa sciencia omni juri, racioni et consuetudini contra hec repugnantibus. Intelligatur tamen quod dictus frater Laurencius teneatur michi dare intus Barchinonam pro nauleo cuiuslibet fratribus unam marcham argenti fini et ponderis recti et pro nauleo etiam cuiuslibet bestie sive equitature cum suo scutifero duas marchas et mediam argenti eiusdem ponderis et valoris. Ad hec ego dictus frater Romeus, comendator domus de Palacio, de assensu et voluntate atque mandato domini fratris Petri de Montecatheno, magistri milicie Templi in Aragonia et Cathalonia, promito nomine ac vice predicti fratris Laurencii sub obligacione bonorum Templi quod predictus frater Laurencius dabit et solvet vobis pro nauleo cuiuslibet fratris unam marcham argenti fini et ponderis recti et pro nauleo cuiuslibet bestie cum suo scutifero duas marchas et mediam argenti et pro nauleo etiam aliorum scutiferorum, si quos plures in dicta navi mitere voluerit, prout consuetum est. Promito etiam vobis quod predicti fratres et bestie cum suis scutiferis et victualibus fuerint in Barchinona in dicto termino preparati de recuyer pro dicto viatico faciendo. Actum est hoc kalendas aprilis anno Domini millesimo 
ducentesimo octuagesimo secundo. Signum Raimundi Marcheti, qui hoc laudo et firmo. Signum fratris Romei Burgeti, comendatoris predicti, qui hoc firmo. Testes huius rei sunt: Petrus Mayol, Huguetus de Cambrils, Arnaldus de Sactis, Jacobus de Canovis et Stephanus de Querchu, presbiter.

\section{NOTES}

1. JOSSERAND, Philippe - Jacques de Molay. Le dernier grand-maitre des Templiers. Paris: Les Belles Lettres, 2019, p. 7.

2. PESSOA, Fernando - Escritos íntimos. Cartas e páginas autobiográficas. Éd. António Quadros. Mem Martins: Pub. Europa América, 1986, p. 252: “Ter sempre na memória o mártir Jacques de Molay, grão-mestre dos Templários, e combater, sempre e em toda a parte, os seus três assassinos - a Ignorância, o Fanatismo e a Tirania”.

3. JOSSERAND, Philippe -“Jacques de Molay en terres ibériques: avatars d'une représentation”. in FERNANDES, Isabel Cristina F. (ed.) - Entre Deus e o rei. 0 mundo das ordens militares. Palmela: Município de Palmela-GEsOS, 2018, t. II, pp. 573-583.

4. JOSSERAND, Philippe -“Jacques de Molay en terres ibériques (...)” ..., p. 575.

5. TELMO, António - História secreta de Portugal. Lisboa: Vega, 1977, p. 59.

6. PARASCHI, André J. - História dos Templários em Portugal: a Fundação e os Mestres. Lisboa: Sol Invictus, 1990; ADRIÃo, Vítor Manuel - Portugal templário: Vida e obra da Ordem do Templo, Lisboa: Via Occidentalis, 2007.

7. costA, Paula Pinto - Templários em Portugal. Homens de religião e de guerra. Barcarena: Manuscrito, 2019, p. 258.

8. costa, Paula Pinto - Templários em Portugal. Homens de religião e de guerra ..., p. 257.

9. costA, Paula Pinto - Templários em Portugal. Homens de religião e de guerra ..., p. 258.

10. costa, Paula Pinto - Templários em Portugal. Homens de religião e de guerra ..., p. 126.

11. GOMES, Saul António - “D. Gualdim Pais (c. 1118/20-1195)”. População e Sociedade 23 (2015), pp. 11-23.

12. costa, Paula Pinto - Templários em Portugal. Homens de religião e de guerra ..., p. 140 et 215.

13. costa, Paula Pinto - Templários em Portugal. Homens de religião e de guerra ..., p. 113 et 186-187.

14. CURzon, Henri de - La Règle du Temple. Paris: Société de l'Histoire de France, 1886.

15. costA, Paula Pinto - Templários em Portugal. Homens de religião e de guerra ..., p. 146.

16. costA, Paula Pinto - Templários em Portugal. Homens de religião e de guerra ..., p. 235.

17. Josserand, Philippe - "Editing Templar Charters in the Iberian Peninsula at the Beginning of the Twenty-First Century". in BORCHARDT, Karl, et. al. (ed.) - The Templars and their Sources. Oxon-New York: Routledge, 2017, pp. 97-98.

18. costa, Paula Pinto - Templários em Portugal. Homens de religião e de guerra ..., pp 146-147; JOSSERAND, Philippe - "Troubles and Tensions before the Trial: the Last Years of the Castilian Templar Province". in EDBURY, Peter (ed.) - The Military Orders, vol. 5: Politics and Power. Farnham: Ashgate, 2012, p. 375. 
19. Une première avancée, encore embryonnaire, avait été procurée par: GOMES, Saul António - "A Extinção da Ordem do Templo em Portugal". Revista da História da Sociedade e da Cultura 11 (2011), p. 85.

20. costA, Paula Pinto - Templários em Portugal. Homens de religião e de guerra ..., p. 146 (tabela 2), 148 (tabela 3) et p. 150.

21. BARROCA, Mário Jorge - "A Ordem do Templo e a arquitectura militar portuguesa do século XII". Portugalia 17-18 (1996-1997), p. 194, sur la base de deux inscriptions lapidaires des châteaux de Tomar et d'Almourol qu'il a publiées peu après (BARROCA, Mário Jorge - Epigrafia medieval portuguesa (862-1422). Lisboa: Fundação Calouste Gulbenkian, 2000, t. I, pp. 348-367, n 136 et 137), où il convient de conserver la lecture de Coine, au lieu de Cione, proposée par REFICE, Paola - "Le epigrafi di Tomar e di Almourol: elementi per lo studio delle fondazioni templari portoghesi". in VITI, Goffredo; CADEI, Antonio; ASCANI, Valerio (ed.) - Monaci in armi. L'architettura sacra dei Templari attraverso il Mediterraneo. Florence: Casa Editrice Certosa Cultura, 1995, pp. 175-186.

22. CLAVERIE, Pierre-Vincent - "Contra soldanum de Coine ou la contribution des Templiers portugais à la défense de la Syrie franque”. in FERNANDES, Isabel Cristina F. (ed.) - As ordens militares e as ordens de cavalaria entre o Ocidente e o Oriente. Actas do V Encontro sobre ordens militares. Palmela: Câmara Municipal de Palmela-GEsOS, 2009, pp.399-412; JOSSERAND, Philippe - "Entre dos frentes: aproximación a las empresas militares de los Templarios del Occidente peninsular (siglos XII-XIV)". in RODRÍGUEZ DE LA PEÑA, Alejandro (ed.) - Hacedores de frontera. Estudios sobre el contexto social de la frontera en la España medieval. Madrid: CEU Ediciones, 2009, pp. 196-200.

23. COSTA, Paula Pinto - Templários em Portugal. Homens de religião e de guerra ..., p. 148.

24. DELAVILLE LE ROULX, Joseph - Documents concernant les Templiers extraits des archives de Malte. Paris: Plon, 1882, p. 354.

25. GOMES, Saul António - "A Extinção da Ordem do Templo em Portugal" ..., p. 97 et p. 105.

26. SCHоттмÜLLER, Konrad - Der Untergang des Templer-Ordens mit urkundlichen und kritischen Beiträgen. Berlin: Mittler und Sohn, 1887, t. II, pp. 170-171, pp. 173-174 et pp. 204-205.

27. JOSSERAND, Philippe - Jacques de Molay. Le dernier grand-maitre des Templiers ..., pp. 126-127 et p. 173.

28. JOSSERAND, Philippe - Jacques de Molay. Le dernier grand-maitre des Templiers ..., p. 165, p. 374, n. 97 , et pp. 451-453, doc. 3.

29. FOREY, Alan - The Templars in the Corona de Aragón. Oxford: Oxford University Press, 1973, p. 325; FOREY, Alan - "Aragonese Templars in the Holy Land and in Cyprus in the Late Thirteenth and Early Fourteenth Centuries". in FERNANDES, Isabel Cristina F. (ed.) - As ordens militares e as ordens de cavalaria entre o Ocidente e o Oriente. Actas do V Encontro sobre ordens militares. Palmela: Câmara Municipal de Palmela-GEsOS, 2009, p. 461.

30. CARRAZ, Damien - "Templiers et négociants méditerranéens: des intérêts convergents". Histoire et images médiévales 46 (2012), p. 32.

31. Aragón, Archivo de la Corona de Aragón, Cancelleria, Pergamins Pere II, 292 (voir l'annexe documentaire). 
32. FOREY, Alan - The Templars in the Corona de Aragón ..., p. 325 et p. 340, n. 145.

33. Cingolani, Stefano - Diplomatari de Pere el Gran. Barcelona: Fundació Noguera, 2011-2015, t. I: Cartes i Pergamins (1258-1285), pp. 453-454, doc. 252.

34. SANS I TRAVÉ, Josep Maria - Els Templers catalans. De la rosa a la creu. Lleida: Pagès, 1996, pp. 271-275; fUGUET SANS, Joan - "La casa del Palau del Temple de Barcelona". Locus amœnus 7 (2004), pp. 99-109.

35. CINGOLANI, Stefano - Diplomatari de Pere el Gran ..., t. I: Cartes i Pergamins (1258-1285), p. 453, doc. 252.

36. JOSSERAND, Philippe - Jacques de Molay. Le dernier grand-maître des Templiers ..., p. 112.

37. FOREY, Alan - The Templars in the Corona de Aragón ..., p. 102.

38. CINGOlani, Stefano - Diplomatari de Pere el Gran ..., t. I: Cartes i Pergamins (1258-1285), pp. 759-760, doc. 430 .

39. BENSCH, Stephen - Barcelona and its Rulers, 1096-1291. Cambridge: Cambridge University Press, 2002, p. 330.

40. SOLDEVILA, Ferran - L'almiral Ramon Marquet. Barcelone. Barcino, 1953.

41. CINGOLANI, Stefano - Diplomatari de Pere el Gran ..., t. II: Relacions internacionals i política exterior (1260-1285), pp. 662-663 et 739, doc. 654 et 770.

42. Aragón, Archivo de la Corona de Aragón, Cancelleria, Pergamins Pere II, 292.

43. CINGOLANI, Stefano - Diplomatari de Pere el Gran ..., t. II: Relacions internacionals i política exterior (1260-1285), t. I: Cartes i Pergamins (1258-1285), pp. 460-461, doc. 258.

44. JOSSERAND, Philippe - Jacques de Molay. Le dernier grand-maître des Templiers ..., p. 165 et p. 374, n. 98.

45. GUzzo, Cristian - "Milites Templi Hierosolimitani in Regno Siciliae. Vecchi documenti, nuove acquisizioni”. in GUzzo, Cristian (ed.) - I Templari nell'Italia centro-meridionale. Storia ed architettura. Tuscania: Penne e Papiri, 2008, pp. 75 et 114, n. 106.

46. STAHULJAK, Zrinka - Pornographic Archaeology: Medicine, Medievalism, and the Invention of the French Nation. Philadelphie: University of Pennsylvania Press, 2013. Trad. fr. de Laurent Bury - L'Archéologie pornographique. Médecine, Moyen Âge et histoire de France. Rennes: Presses universitaires de Rennes, 2018, p. 125.

47. ELM, Kaspar - "Gli ordini militari: un ceto di vita religiosa fra universalismo e particolarismo". in MARCO, Maria de; TOMMASI, Francesco (eds.) - Militia Sacra. Gli ordini militari tra Europa e Terrasanta. Pérouse: Società Editrice San Bevignate, 1994, pp. 9-28; ELM, Kaspar - "Die Ordines militares. Ein Ordenszötus zwischen Einheit und Vielfalt". in HUNYADI, Zsolt; LASZLOVSKY, József (eds.) - The Crusades and the Military Orders. Expanding the Frontiers of Medieval Latin Christianity. Budapest: Central European University, 2001, p. 351-377.

48. SARNOWSKY, Jürgen - "Mendicants, Military Orders, and Regionalism". in SARNOWSKT, Jürgen (ed.) - Mendicants, Military Orders, and Regionalism in Medieval Europe. Aldershot: Ashgate, 1999, p. 285.

49. DEMURGER, Alain - "L'étude des ordres religieux-militaires en France: la fin de la marginalité ? Introduction au dossier". Cahiers de recherche médiévale. A Journal of Medieval Studies 15 (2008), p. 171. 
50. JosSeRAnD, Philippe - Jacques de Molay. Le dernier grand-maître des Templiers ..., pp. 157-176 et 367-388.

51. DAILLIEZ, Laurent - Jacques de Molay, dernier maître du Temple. Paris: Dumas, 1974, p. 176.

52. OLIVEIRA, Luís Filipe - "Uma História às Avessas. A Historiografia do Templo em Portugal". in FERNANDES, Isabel Cristina F. (ed.) - Entre Deus e o rei. 0 mundo das ordens militares. Palmela: Município de Palmela-GEsOS, 2018, t. II, pp. 671-684.

53. TOOMASPOEG, Kristjan - "Historiographie de l'ordre du Temple au Portugal: status quastionis”. in CARREIRAS, José Albuquerque; VAIRO, Giulia Rossio (ed.) - I Colóquio internacional. Cister, os Templários e a ordem de Cristo. Tomar: Instituto Politécnico de Tomar, 2012, pp. 171-183.

54. oliveirA, Luís Filipe - "Uma História às Avessas. A Historiografia do Templo em Portugal" ..., t. II, p. 676 et p. 678.

55. oliveIRA, Luís Filipe - "The Military Orders in the Twelfth-Fourteenth Centuries". in MATTOSO, José (ed.) - The Historiography of Medieval Portugal, c. 1950-2010. Lisboa: Instituto de Estudos Medievais, 2011, p. 432; Josserand, Philippe - "Jacques de Molay acteur hispanique? Au carrefour des représentations, de la mémoire et de l'histoire". in AYALA MARTÍNEZ, Carlos; PALACIOS ONTALVA, Santiago; Ríos SALOMA, Martin - Guerra santa y cruzada en el estrecho: el Occidente peninsular en la primera mitad del siglo XIV. Madrid: Sílex, 2016, p. 444.

56. VALENTE, José - "Soldiers and Settlers. The Knights Templar in Portugal, 1128-1319". Santa Barbara: University of California, 2002. Thèse de doctorat, pp. 116-117 et pp. 121-122; SILVA, Luiz Ademir da - "Da cruzada à demanda. A tradição épica da ordem dos Templários na Baixa Idade Média portuguesa (séculos XII-XIV)". Goiânia: Universidade Federal de Goiás, 2008. Thèse de doctorat, 2008, pp. 28-43; FERNANDES, Maria Cristina - A Ordem do Templo em Portugal das origens à extinção. Porto: Universidade do Porto, 2009. Thèse de doctorat, pp. 170-172, p. 214 et p. 229.

57. FARELO, Mário - "Pro defensione iuris regis. Les relations entre la Couronne portugaise et le pape Clément $\mathrm{V}$ à la lumière du procès des Templiers". in CARREIRAS, José Albuquerque (ed.) - A Extinção da Ordem do Templo. Tomar: Instituto Politécnico de Tomar, 2012, pp. 63-109, p. 73; cosTA, Paula Pinto - "Templários no condado portucalense antes do reconhecimento formal da ordem: o caso de Braga no início do século XII". Revista da Faculdade de Letras do Porto. Ciências e Técnicas do Património 12 (2013), p. 241; costA, Paula Pinto - Templários em Portugal. Homens de religião e de guerra ..., p. 235.

58. GOMES, Saul António - "Observações em torno das Chancelarias das Ordens Militares em Portugal na Idade Média". in FERNANDES, Isabel Cristina F. (ed.) - As ordens militares $e$ as ordens de cavalaria na construção do mundo ocidental. Actas do IV Encontro sobre ordens militares. Palmela: Município de Palmela-GEsOS, 2009, p. 128; GOMES, Saul António - "A Extinção da Ordem do Templo em Portugal", pp. 82-83, 86-88 et 97-98.

59. oliveira, Luís Filipe - "Ordem militar do Templo". in VASCONCELOS E SOUSA, Bernardo (ed.) - Ordens religiosas em Portugal. Das origens a Trento. Guia Histórico. Lisboa: Livros Horizonte, 2005, p. 463; olIVEIRA, Luís Filipe - "The Military Orders in the Twelfth-Fourteenth Centuries"..., p. 431-433. 
60. toomaspoeg, Kristjan - "Historiographie de l'ordre du Temple au Portugal: status quoestionis"..., p. 187.

61. toomASPoeg, Kristjan - "L'ordre du Temple en Occident et au Portugal". in CARREIRAS, José Albuquerque (ed.) - A Extinção da Ordem do Templo. Tomar: Instituto Politécnico de Tomar, 2012, p. 20.

62. FOREY, Alan - The Templars in the Corona de Aragón ..., p. 323.

63. DEMURGER, Alain - Les Templiers. Une chevalerie chrétienne au Moyen Âge. Paris: Seuil, 2005, p. 334.

64. JOSSERAND, Philippe -"De l'arrière au front: regards sur la logistique des ordres militaires au Moyen Âge". in FERNANDES, Isabel Cristina F. (ed.) - As ordens militares. Freires, guerreiros, cavaleiros. Actas do VI Encontro sobre ordens militares. Palmela: Município de Palmela-GEsOS, 2012, t. II, pp. 686-690; JOSSERAND, Philippe - Jacques de Molay. Le dernier grand-maitre des Templiers ..., pp. 166-168 et pp. 374-377.

65. FOREY, Alan - "Notes on Templar Personnel and Government at the Turn of the Thirteenth and Fourteenth Centuries". Journal of Medieval History 35 (2009), p. 160.

66. JOSSERAND, Philippe - "Entre Orient et Occident: l'ordre du Temple dans le contexte castillan du règne d'Alphonse X". Alcanate. Revista de Estudios Alfonsíes 2 (2000-2001), p. 136; JOSSERAND, Philippe - Église et pouvoir dans la péninsule Ibérique. Les ordres militaires dans le royaume de Castille (1252-1369). Madrid: Casa de Velázquez, 2004, p. 596.

67. CARRAZ, Damien - L'Ordre du Temple dans la basse vallée du Rhône (1124-1312). Ordres militaires, croisades et sociétés méridionales. Lyon: Presses universitaires de Lyon, 2005, pp. 260 et 457-458; BELlomo, Elena - The Templar Order in the North-West Italy (1142-c. 1330). Leyde-Boston: Brill, 2008, p. 44; BELLomo, Elena - "Templari, Oriente, crociata: percorsi di ricerca in Italia settentrionale". in FERNANDES, Isabel Cristina F. (ed.) - As ordens militares. Freires, guerreiros, cavaleiros. Actas do VI Encontro sobre ordens militares. Palmela: Município de Palmela-GEsOS, 2012, t. II, p. 801.

68. OLIVEIRA, Luís Filipe - "Uma História às Avessas. A Historiografia do Templo em Portugal" ..., t. II, p. 679.

69. "Vita Martini Sauriensis". in NASCIMENTO, Aires A. - Hagiografia de Santa Cruz de Coimbra. Lisboa: Colibri, 1998, p. 241; COSTA, Paula Pinto - "Templários no condado portucalense antes do reconhecimento formal da ordem: 0 caso de Braga no início do século XII"..., pp. 233-234. Appuyée sur des copies du XvI ${ }^{e}$ siècle, la datation de l'auteure est incertaine et elle-même a récemment concédé que, même si à ses yeux un doute demeure, les actes du Minho pourraient en réalité être de trente ans postérieurs (COSTA, Paula Pinto - Templários em Portugal. Homens de religião e de guerra ..., pp. 73-76).

70. oliveira, Luís Filipe - "Ordem militar do Templo" ..., p. 462; TOOMASPOEG, Kristjan "L'ordre du Temple en Occident et au Portugal" ..., p. 27.

71. GOMES, Saul António - Pombal medieval e quinhentista. Documentos para a sua história. Leiria: Centro do Património de Estremadura, 2010, p. 81, doc. 1.

72. SANS I TRAVÉ, Josep Maria - Arnau de Torroja: un Català mestre major de l'orde del Temple (1118/1120 ?-1184). Barcelone: Reial Acadèmia de Bones Lletres de Barcelona, 2006, p. 128. À Vérone, en 2016, une tombe qui pourrait être celle du dignitaire a été découverte fortuitement dans la cour de San Fermo Maggiore (BAGNI, Giampiero - "The 
Sarcophagus of Templar Master Arnau de Torroja in Verona? Sources and Scientific Analysis". Crusades, 17 (2018), pp. 31-38).

73. GOMES, Saul António - "Observações em torno das Chancelarias das Ordens Militares em Portugal na Idade Média”, p. 159, doc. 4; VENTURA, Leontina; RESENDE DE OLIVEIRA, António - Chancelaria de D. Afonso III. Livro I. Coimbra: Imprensa da Universidade de Coimbra, 2006, t. II, p. 116, doc. 526.

74. GOMES, Saul António - "A presença das ordens militares na região de Leiria (séculos XII-XIV)”. in FERNANDES, Isabel Cristina F.; PACHECO, Paulo (ed.) - As ordens militares em Portugal e no Sul da Europa. Lisboa-Palmela: Colibri-Câmara Municipal de Palmela, 1997, p. 179 , doc. 11 .

75. JOSSERAND, Philippe - Jacques de Molay. Le dernier grand-maitre des Templiers ..., p. 175.

76. FINKE, Heinrich - Papsttum und Untergang des Templerordens. Münster: Aschendorff, 1907, t. II: Quellen, p. 37, doc. 24.

77. CONDE y DELGADo De molina, Rafael; Pujades i batAller, Ramón José - "Epistolario de Jacques de Molay y cartas manuscritas de los Templarios". in ALVAR EZQUERRA, Carlos et. al. (eds.) - Secretum Templi. Valencia: Grial, 2005, t. III, pp. 108-109.

78. FOREY, Alan - "The Career of a Templar: Peter of St Just". in HOUSLEY, Norman Knighthoods of Christ. Essays on the History of the Crusades and the Knights Templar, Presented to Malcolm Barber. Aldershot: Ashgate, 2007, p. 183.

79. JOSSERAND, Philippe - Jacques de Molay. Le dernier grand-maitre des Templiers ..., p. 195 et pp. 409-410.

80. FOREY, Alan - "Letters of the Last Two Templar Masters". Nottingham Medieval Studies 45 (2001), p. 160, doc. 1.

81. PAGAROLAS I SABATÉ, Laureà - Els Templers de les terres de l'Ebre (Tortosa). De Jaume I fins a l'abolició de l'orde (1213-1312). Tarragona: Diputació de Tarragona, 1999, t. II, pp. 197-198, doc. 171; FOREY, Alan - "Letters of the Last Two Templar Masters" ..., p. 166, doc. 13.

82. JOSSERAND, Philippe - Jacques de Molay. Le dernier grand-maître des Templiers ..., p. 195.

83. FINKE, Heinrich - Papsttum und Untergang des Templerordens ..., t. II: Quellen, p. 37, doc. 24. De Miravet, sur l'Èbre, Pere de Santjust a écrit: "Senyor, con vostra [ven]guda sia molt profitosa et molt honorable a nos et al Temple, nomenadament nos sera molt profitosa et honorable de venir en esta terra et melorar senhia molt lestament del Temple, et axi seria molt profitosa la vostra entrada de Castela et de Portogal, segons quens ha fet saber a letres alcuns frares daqueles partides".

84. PIZARRO, José Augusto de Sotto Mayor - D. Dinis, Lisboa: Círculo de Leitores, 2005, p. 172.

85. SÁ nogueIRA, Bernardo de - O Livro das Lezírias d'el-rei Dom Dinis. Lisboa: Centro de História da Universidade de Lisboa, 2003, pp. 162-165, doc. 50.

86. FARELO, Mário - "Pro defensione iuris regis. Les relations entre la Couronne portugaise et le pape Clément $\mathrm{V}$ à la lumière du procès des Templiers" ..., pp. 63-109, 2012, p. 71 et pp. 103-105.

87. SÁ NogueIRA, Bernardo de - O Livro das Lezírias d'el-rei Dom Dinis ..., p. 234-236, doc. 73, et p. 240-242, doc. 74: "E entom o dicto maestre e freyres disserom consentindo na dicta sentença que lhis dessemos tempo pera mandarem a alem mar faze-lo saber a seu 
mayor e que queriam auer conselho con ele e que queriam ala mandar por cartas e por priuilegios que diziam que tijnham con que diziam que poderiam deffender o seu direito".

88. MARTínez díez, Gonzalo - Los Templarios en la Corona de Castilla. Burgos: La Olmeda, 1993, p. 44 et 53; AYALA MARTínez, Carlos de - "Las órdenes militares y los procesos de afirmación monárquica en Castilla y Portugal (1250-1350)”. in FONSECA, Luís Adão da (ed.) - As relações de fronteira no século de Alcanices. Actas das IV Jornadas luso-espanholas de história medieval. Porto: Imprensa da Universidade do Porto, 1998, t. II, pp. 1279-1312; AYALA MARTíNEZ, Carlos de - "Frontera castellano-leonesa y órdenes militares. Problemas de jurisdicción (siglos XII-XIII)". in ÁlVAREZ PALENZUeLA, Vicente -Jornadas de cultura hispano-portuguesa. Madrid: Universidad Autónoma de Madrid, 1999, p. 69; AYALA MARTíNEZ, Carlos de - "Fernando III y las órdenes militares". in PEÑA SOLAR, Juan Ignacio de la - Fernando III y su tiempo (1201-1252). Congreso de estudios medievales. Ávila: Fundación Sánchez-Albornoz, 2003, p. 83.

89. JOSSERAND, Philippe - "Et succurere Terre sancte pro posse: les Templiers castillans et la défense de l'Orient latin au tournant des XIII et XIV $^{\mathrm{e}}$ siècles". Cahiers de recherches médiévales. A Journal of Medieval Studies, 15 (2008), p. 218.

90. FERNANDEZ RUIZ, Raquel del Carmen - Colección diplomática del monasterio de Santo Domingo de Benavente (1228-1390). Benavente: Centro de Estudios Benaventanos Ledo del Pozo, 2000, p. 65, doc. 27.

91. BORCHARDT, Karl - "The Military-Religious Orders: A Medieval "School for Administrators"?". in EDBURY, Peter (ed.) - The Military Orders. Vol. 5. Politics and Power. Farnham: Ashgate, 2012, p. 7.

92. JOSSERAND, Philippe -"De l'arrière au front: regards sur la logistique des ordres militaires au Moyen Âge", t. II, pp. 694-695.

93. RILEY-SMITH, Jonathan - "Towards a History of Military-Religious Orders". in BORCHARDT, Karl; JASPERT, Nikolas; NICHOLSON, Helen (ed.) - The Hospitallers, the Mediterranean and Europe. Festschrift for Anthony Luttrell. Aldershot: Ashgate, 2007, pp. 276-277; BORCHARDT, Karl - "The Military-Religious Orders: A Medieval "School for Administrators"?" ..., p. 12; JOSSERAND, Philippe - Jacques de Molay. Le dernier grandmaître des Templiers ..., p. 170.

94. Pour l'essentiel, les travaux du Sonderforschungsbereich de Dresde, opératif entre 1996 et 2008 - dont on peut avoir un parfait aperçu des principes rédigé par celui qui les a inspirés [MELVILLE, Gert - "La recherche sur les ordres religieux en Allemagne. Chemins parcourus et nouveaux horizons". Cahiers de civilisation médiévale 49 (2006), pp. 163-174, p. 163-174] - et prolongé depuis par la Forschungsstelle für Vergleichende Ordensgeschichte, ont laissé le Temple et ses émules de côté, tout comme l'a fait, dans son très bel essai, DALARUN, Jacques - Gouverner c'est servir. Essai de démocratie médiévale. Paris: Alma, 2012.

95. FOREY, Alan - "Royal and Papal Interference in Dispatch of Supplies to the East by the Military Orders in the Later Thirteenth Century". in EDBURY, Peter (ed.) - The Military Orders. Vol. 5: Politics and Power. Farnham: Ashgate, 2012, p. 102.

96. NICHOLSON, Helen - "International Mobility versus the Needs of the Realm: the Templars and Hospitallers in the British Isles in the Thirteenth and Fourteenth Centuries“. in BURGTORF, Jochen; NICHOLSON, Helen (ed.) - International Mobility in the 
Military Orders (Twelfth to Fifteenth Centuries). Cardiff: University of Wales Press, 2006, p. 91.

97. JOSSERAND, Philippe - Jacques de Molay. Le dernier grand-maître des Templiers ..., p. $175-176$.

98. VOGEL, Christian - "Die Templer in Mitteleuropa und ihre Organisationsstrukturen". in BORCHARDT, Karl; JAN, Libor (ed.) - Die geistlichen Ritterorden in Mitteleuropa Mittelalter. Brno: Matice moravská, 2011, p. 166; Karl BORCHARDT, Karl - "The Templars and the Thirteenth-Century Colonisation in Eastern Central Europe". In BAUDIN, Arnaud; BRUNEL, Ghislain; DOHRMANN, Nicolas (eds.) - L'Économie templière en Occident. Patrimoines, commerce, finances. Langres: Guéniot, 2013, pp. 438-441.

99. BERTHEL, Alex - "Die Templer im Gebiet östlich der Elbe zur Aufhebung des Ordens (1312)". Sacra Militia. Rivista di storia degli ordini militari 1 (2000), pp. 13-54; BORCHARDT, Karl - "The Templars in Central Europe". in HUNYADI, Zsolt; LASZLovsKY, József (eds.) The Crusades and the Military Orders. Expanding the Frontiers of Medieval Latin Christianity. Budapest: Central European University, 2001, pp. 237-238.

100. FOREY, Alan - The Templars in the Corona de Aragón ..., p. 324.

101. NICHOLSON, Helen - "How Secret was the Templar Admission Ceremony? Evidence from the Proceedings in Britain and Ireland". in SAMMARCO, Sergio - Conmilitones Christi. Miscellanea di studi per il Centro Italiano di Documentazione sull'Ordine del Tempio. Rome: Lisanti, 2016, p. 89.

102. NICHOLSON, Helen -The Proceedings against the Templars in the British Isles. Farnham: Ashgate, 2011, t. I, p. 192, et t. II, p. 204.

103. JOSSERAND, Philippe - "Entre dos frentes: aproximación a las empresas militares de los Templarios del Occidente peninsular (siglos XII-XIV)” ..., pp. 179-201.

104. JOSSERAND, Philippe; BERIOU, Nicole (ed.) - Prier et combattre. Dictionnaire européen des ordres militaires au Moyen Âge. Paris: Fayard, 2009.

105. JOSSERAND, Philippe - Église et pouvoir dans la péninsule Ibérique. Les ordres militaires dans le royaume de Castille (1252-1369) ..., p. 24-25.

106. FIOLHAIS, Carlos; FRANCO, José Eduardo; PAIVA, José Pedro (ed.) - História global de Portugal. Lisboa: Círculo de Leitores, 2020.

107. BOUCHERON, Patrick (ed.) - Histoire mondiale de la France. Paris: Seuil, 2017.

* La cote utilisée aujourd'hui ne doit pas tromper, car, second roi du nom de Pierre en Catalogne, le souverain est plus généralement connu et cité - ainsi que je l'ai fait dans l'article - comme Pierre III d'Aragon.

\section{RÉSUMÉS}

Au Portugal, le Temple a longtemps été pensé en dehors de l'Orient latin et il le reste encore sauf exceptions comptées. L'idée prévaut, même chez les spécialistes, que la province portugaise de l'ordre, bénéficiant d'une autonomisation graduelle, aurait connu, à la fin du XIII ${ }^{\mathrm{e}}$ siècle, un 
éloignement définitif de la Terre sainte. Pour battre en brèche ce préjugé, l'étude s'appuie sur un document inédit conservé à l'Archivo de la Corona de Aragón qui, en 1282, implique Lourenço Martins, lieutenant du maître provincial de Portugal, dans un transport méditerranéen de Barcelone à Acre. Celui-ci s'est opéré avec quatre frères, quarante-cinq à cinquante bêtes, accompagné des écuyers et des victuailles leur correspondant. À l'époque, il n'avait rien de singulier et il s'inscrit dans une tradition de relations entre le Portugal et l'Orient latin qui reste très méconnue. Les Templiers n'en étaient pas les seuls acteurs, mais ils y ont joué un rôle crucial, qui infirme le caractère national si volontiers prêté à leur ordre au pays de Fernando Pessoa et d'un templarisme toujours vif.

In Portugal, the Temple has long been thought as having no connections with the Latin East and it still remains so with few exceptions. Even among specialists, it is still admitted that the Portuguese province of the order, by benefiting from a gradual autonomy, would have known a definitive estrangement from the Holy Land at the end of the thirteenth century. To challenge this preconceived idea, it is used in this paper an unpublished document kept in the Archivo de la Corona de Aragón which, in 1282, implicates Lourenço Martins, lieutenant of the provincial master of Portugal, in a Mediterranean transport from Barcelona to Acre. He would travel with four brothers, forty-five to fifty animals, accompanied by the squires and their corresponding bales and supplies. At the time, such shipments were not uncommon. They formed part of a tradition of contacts between Portugal and the East which remains largely unknown. The Templars were certainly not the only agents of this relationship, but they played a crucial role, which undermines the national character so readily lent to their order in the land of Fernando Pessoa and of an ever-lively Templarism.

\section{INDEX}

Mots-clés : Ordre du Temple, transferts

Keywords : Portugal

\section{AUTEUR}

\section{PHILIPPE JOSSERAND}

Université de Nantes, Département d'Histoire, Chemin la Censive du Tertre, B.P. 81227, 44312

Nantes Cedex 3, France. ph.josserand@wanadoo.fr 